\title{
Analysis on the Socialization of Criminal Vocational and Technical Education
}

\author{
Juan Liu ${ }^{1, a}$ \\ ${ }^{1}$ Sichuan Vocational College of Judicial Police, Deyang 618000, Sichuan Province \\ a2014326215@dlvtc.edu.cn
}

\begin{abstract}
Criminal vocational and technical education is a labor skill training activity carried out by prisons based on the needs of prison production and employment after the prisoners are released. It is an important part of the education and reformation of criminals in my country. This article attempts to sort out the current problems in the socialization of vocational and technical education for prisoners, and proposes a path for the socialization of vocational and technical education for offenders, in order to improve the level of vocational and technical education for offenders and promote the quality of prison reform.
\end{abstract}

Keywords: criminals, vocational and technical education, socialization, thinking and analysis

\section{POLICIES RELATED TO VOCATIONAL AND TECHNICAL EDUCATION FOR OFFENDERS}

Article 70 of the "Prison Law of the People's Republic of China" "According to the prisoner's personal circumstances, the prison organizes labor rationally to correct bad habits, develop labor habits, learn production skills, and create conditions for employment after release." The significance and role of criminal vocational and technical education in the execution of penalties. After years of practice and hard work, vocational and technical education for prison inmates has achieved certain results, but the degree of socialization is not high. The multiple and multi-dimensional operating system of prison and social forces on vocational and technical education for offenders needs to be further constructed ${ }^{[1]}$.

\section{THE SIGNIFICANCE OF THE SOCIALIZATION OF CRIMINAL VOCATIONAL AND TECHNICAL EDUCATION}

(1) Enhancing the enthusiasm of criminal reformation and improving the quality of prison education and reformation

Rebuilding the values of criminals and correcting the wrong thoughts of criminals is one of the important tasks of prison education and reform of criminals, which requires multiple means and multiple dimensions. Among them, organizing criminals to participate in labor and mastering labor skills and technology is an effective means to cleanse the criminals' minds. This requires not only external forces, but also the criminals' own initiative and enthusiasm. Prisons make full use of social resources, based on the basic rights and interests of criminals, their own conditions, professional expectations and social needs, and choose appropriate skill training programs to fully mobilize the criminals' subjective learning initiative and actively participate in vocational and technical education. For example: use the psychology of foreign monks to recite scriptures to introduce social teachers; use the curiosity of criminals to use novel social teaching methods to increase the interest of criminals; create an active learning atmosphere through labor skill competitions and the establishment of labor reform activists; Criminals who actively participate in vocational and technical education will be given corresponding rewards, such as granting scholarships, scoring assessments, etc., to mobilize their subjective initiative and enthusiasm, and improve the quality of criminal education and reform under the benign mutual promotion of other educational reform methods ${ }^{[2]}$.

(2) Improve the re-socialization level of criminals and reduce re-offending

After the prisoner is released after serving his sentence, he is faced with the problems of social 
adaptation and survival. Due to lack of skills, some criminals may take risks and commit crimes again in order to maintain their lives after they are released from prison. Therefore, allowing criminals to learn and master at least one technique is an effective means to improve the level of re-socialization of criminals and reduce re-offending. The socialization of offenders' vocational and technical education can make full use of social resources and social teaching models, allowing offenders to experience social work and life that keeps pace with the times in the prison, thereby facilitating the running-in with the society and the job after release, and thus smooth adaptation Society, reduce the possibility of crime again.It is undeniable that in the process of execution, criminals may be out of touch with society, do not understand the current development of society, or lack the ability to adapt to social occupations. When they are released after serving their sentence, they will most likely become a factor restricting the harmony and stability of the society because of their inability to gain a foothold. For this reason, it is necessary to effectively improve the social adaptability of criminals through scientific and precise social education of professional criminals, actively guide them to grasp the development trend of society, and effectively improve their job adaptability, so as to help them integrate into society in the future. Make preparations for consolidation.

(3) Reduce the work pressure of prison police

Prison work is complicated, with heavy tasks such as penalty enforcement, education reform, prison administration management, and life hygiene. In addition, most of the prison police officers are from non-disciplinary classes, lacking professional vocational skills and education and teaching skills, which may lead to heavy work pressure and separation of police officers. Lack of skills and unsatisfactory teaching effect.Socializing criminal vocational and technical education, introducing social institutions, and assigning "professional work to professional people" will not only liberate the police from criminal vocational and technical education, but also effectively improve the utilization of social resources. Improve the quality of education.In the practice of some prison management, vocational and technical education of criminals is often handed over to the prison police.But in fact, prison police may lack professionalism in this area, and may lack practical knowledge in this area. It is difficult to truly grasp the direction of education in the process of professional and technical education of criminals, and it is also difficult to improve the quality of education. It will bring greater pressure to themselves, severely affect and restrict their work effectiveness. To this end, actively and effectively promote the socialization of vocational and technical education, fully and comprehensively utilize a wide range of social resources, effectively and effectively improve the overall level and intensity of criminal vocational and technical education, and better promote their professional development.It can be said that the introduction of social resources can not only guarantee the professionalization, modernization, and rigorization of criminal vocational and technical education as a whole, but also release the work pressure of the majority of prison police to a large extent and guide them to better develop their professions. Management ${ }^{[3]}$.

(4) People-oriented embodying the deep rational value of punishment

In the process of reforming criminals to serve their sentences, actively giving them vocational and technical education can not only help them better reform themselves, but also improve their professional abilities to a large extent and help them effectively adapt to the needs of social development.It can be said that in the process of reforming criminals to serve their sentences, vocational and technical education is actively promoted, which deeply and comprehensively reflects the human-oriented deep rational value of criminal law.Although criminals have been deprived of their political rights, their other rights still exist.In the process of reforming and educating criminals, we should attach great importance to vocational and technical education to help them form correct norms and cognitions to help them truly master a skill in order to better adapt to future social positions.In the course of practice, the prison actively uses social resources, actively introduces specialized social institutions, and effectively develops vocational and technical education. This not only provides the necessary development space for criminals, but is also an important idea for comprehensively practicing humanistic management.Interpreting people-oriented from the perspective of human nature is to tap the most basic needs of human nature, and continuously meet and improve people's material and spiritual life needs. This is the most fundamental foundation and value trend of people-oriented.In the process of reforming criminals serving sentences, actively establish a people-oriented development concept, scientifically and comprehensively reform and innovate vocational and technical education methods and methods to provide criminals with room for growth and development, which can promote their development and progress to a large extent. It is also a direct manifestation of prison humanistic management.

\section{PROBLEMS IN THE SOCIALIZATION OF CRIMINAL VOCATIONAL AND TECHNICAL EDUCATION}

(1) The socialization of criminal vocational and technical education lacks a solid guarantee

The development of criminal vocational and technical education requires top-level design and system construction, as well as the support of policies and funds, 
as well as the coordination of the government and society.However, at present, there has not been a systematic establishment of an effective model and guarantee system for the socialized operation of criminal vocational and technical education. Many prisons are in a situation of self-exploration and self-contained systems or fighting alone.In the process of the socialization of criminal vocational and technical education, there has been a craze for the prison side, while the participation of social institutions is low, and confidence is insufficient; there is powerlessness, ideas but no implementation, and no effective socialized operation mode of criminal vocational and technical education for reference, etc. Happening.It can be said that at this stage, in the process of implementing criminal vocational and technical education in prisons, there is a lack of overall design and overall management, which will affect the effective development of criminal vocational and technical education to a large extent.Vocational and technical education for criminals is a rigorous and systematic comprehensive work. In the process of development, it is necessary to explore an all-round and three-dimensional education development model to fully and comprehensively coordinate the efforts of all parties.But at this stage, in the process of carrying out criminal vocational and technical education, there is still a lack of a complete guarantee system and operating mechanism, which will undoubtedly restrict its scientific and effective development to a large extent, and it is also difficult to guarantee its implementation. Quality and operational level.

(2) Inadequate socialization of criminal vocational and technical education, with a tendency to formalize

In recent years, the development trend of the socialization of criminal vocational and technical education has been relatively good, but due to many factors, the socialization of criminal vocational and technical education has shown a certain superficial phenomenon.At present, some prisons' vocational and technical education for offenders does not fully investigate market needs. It is based on the existing production and labor projects in prisons, and adopts "whatever the prison does and learns", which may lead to mismatched employment and skills that do not meet the requirements of the job. , Slow to get started and poor adaptability, even unable to adapt to social needs.This relatively blind vocational education technology method will not only cause a serious waste of social resources, but it will also be difficult to truly improve and optimize the criminal's professional and technical capabilities, and even restrict the development of criminals to a large extent.Scientific vocational and technical education should be based on the development needs of the society at this stage, continuously add new content, continuously expand new methods, and maximize the intensity of its vocational education to ensure that vocational education truly achieves practical
results.However, at this stage, there is still a lack of a good operating system and necessary social research in the development of criminal vocational and technical education, which easily makes criminal vocational and technical education into a relatively difficult situation, and it is difficult to effectively improve criminal vocational and technical education. The full-scale development of the science of the crime cannot really improve the professional and technical capabilities of criminals.Some prisons have only reached cooperation intentions with social institutions and established a basis for cooperation, but they have not fully organized relevant educational activities in accordance with actual needs and teaching goals. This kind of formal criminal vocational and technical education can hardly improve the overall strength of criminal vocational and technical education, and it is also difficult to optimize the development level of criminal vocational and technical education, and it may even cause a serious waste of social resources.In some prisons, the vocational and technical education of criminals has re-fulfilled the indicators prescribed by the superior, the inspection and acceptance by the superior, and the form of education. The social resources have not been fully tapped and used, and the degree of socialization is not high ${ }^{[4]}$.

\section{THINKING ON THE SOCIALIZATION PATH OF CRIMINAL VOCATIONAL AND TECHNICAL EDUCATION}

(1) Overall planning and coordinating, including criminal vocational and technical education into local development plans

Criminals serving sentences in prisons are a member of the national education system and an important part of human resources. Vocational and technical education for prison inmates is an important part of human resource development and cannot be a forgotten corner.With the country's vigorous development of vocational education, the integration of criminal vocational and technical education with society will be further deepened.Further implement the work requirements of "incorporating criminal cultural education and vocational skills training into local planning", incorporate the development of criminal vocational and technical education into the local development plan, and coordinate the organization of criminal vocational and technical education by the local government, and actively integrate the government, prisons, and vocational colleges. Resources to ensure the regularization, scientification and socialization of technical education for prison inmates.In the process of practice, actively and effectively promote the in-depth development of criminal vocational and technical education to ensure that the majority of criminals in prison can obtain adequate vocational education opportunities and can effectively improve their 
vocational skills. It is necessary to scientifically and comprehensively build and improve A standardized and unified criminal vocational education system.In the criminal vocational education system, the main responsibilities of different departments should be fully and comprehensively clarified, and the key roles of different departments should be fully utilized to truly form a development force to maximize the reeducation ability of criminals serving sentences.It is undeniable that in the traditional criminal vocational education system, the prison often plays a subjective role. However, in the specific implementation and development process, it lacks overall coordination with other departments, and has not formed a real development joint force. This will undoubtedly To a large extent, it affects the scientific and orderly development of criminal vocational and technical education, and it is difficult to guarantee the in-depth advancement of this work.For this reason, it is necessary to continuously integrate advantageous resources from the height of local economic development and regional stability, scientifically construct a cultivation system, effectively and effectively build a sound vocational education system, and actively establish a sound vocational education mechanism for criminals to ensure this The work has been carried out in an in-depth and comprehensive manner to better improve the professionalism of criminals ${ }^{[5]}$.

(2) Innovating the socialized school-running model of criminal vocational and technical education

On the basis of the in-depth promotion of criminal cultural education and vocational education into the local development plan, the implementation of a joint school model led by the local party committee, led by the administrative department at the municipal level, and integrated and participated by the educational resources of each school. Intensify pilot projects, strengthen cooperation with local vocational and technical schools, strive to form a part-time joint school model for criminal vocational and technical education with strong market adaptability, diversification, and characteristics, and explore "prison + school", "master with apprentice", and "concentration" Educational models such as "teaching + self-selected learning + customized training", "in-prison simulation training + out-of-prison training base", effectively promote the extension of criminal vocational and technical education, and conduct experience summarization and promotion. In the process of vocational and technical education for criminals, it is far from enough to rely solely on the strength of the prison or the prison police to play the role of vocational education. For this reason, in the course of practice, efforts should be made to promote the in-depth and comprehensive promotion of criminal vocational and technical education, and to effectively and effectively improve the overall development of criminal vocational and technical education.In practice, it is necessary to combine the development of criminal vocational and technical education, scientifically and comprehensively construct a sound education model, and actively add brand-new education programs to ensure that the majority of criminals can receive professional vocational education during the period of prison reform. In the specific vocational education process, the prison authorities should actively cooperate with local colleges, education and training institutions, etc. under the guidance of higher-level departments, jointly explore the establishment of a comprehensive training model, and actively and effectively promote Professional and systematic development of criminal vocational and technical education.

(3) Change thinking and formulate a scientific training system

First of all, prisons must actively change their thinking and formulate scientific training programs. Vocational and technical education for criminals must be forward-looking, fully research the market and actual needs of social employment, and combine the characteristics and cultural foundation of criminals. When configuring relevant education curriculum systems, it is necessary to strictly follow social needs and formulate training programs step by step.The purpose of criminal vocational and technical education in prisons is to guide the majority of criminals to master solid vocational skills, continuously improve their own professional qualities, effectively optimize their job adaptability and social adaptability, and guide and help them truly master a skill. For this reason, in the process of developing vocational and technical education, it is necessary to build on the basis of extensive and scientific social research, and it is necessary to build on the basis of in-depth and comprehensive job surveys, so as to scientifically and comprehensively construct a comprehensive education. Personnel program, effectively improve the effectiveness and accuracy of criminal vocational and technical education.Second, use scientific teaching methods. Follow the law of the learning characteristics of criminals and the progressive vocational ability, learn from the experience and methods of vocational and technical education in the society, and adopt appropriate teaching methods and encouragement measures to ensure that criminals are willing to learn, use what they learn, and achieve success.In the process of criminal vocational and technical education, in addition to continuously innovating education and teaching methods and actively expanding training programs, efforts should also be made to reform and optimize assessment and incentive methods. For criminals, they also need certain incentive measures in the process of vocational and technical education to effectively enhance their self-confidence. Some criminals are not well-educated. In the process of learning technology, it may be difficult for them to devote themselves to it. Coupled with their relatively 
serious psychological burden, it will also affect their vocational and technical learning effectiveness. For this reason, it is necessary to scientifically and comprehensively explore the establishment of an efficient incentive system, so as to better enhance the enthusiasm of the majority of criminals to learn, encourage them to actively learn, actively reform themselves, actively improve their technical literacy, and return as soon as possible. life.

(4) Take multiple measures simultaneously to use social resources

Strengthen cooperation with social organizations and vocational schools in training projects, teaching plans, loose-leaf textbooks, theoretical explanations, practical training programs, teacher training, skills assessment, and skills appraisal. First, strengthen the construction of the teaching staff, implement the training plan, and improve the quality of teaching. The construction of teachers for criminal vocational and technical education should combine "hematopoiesis" and "blood transfusion." According to designated vocational skills training institutions recognized by the human resources and social security departments, scientific and reasonable arrangements for criminal vocational skills trainers, conduct professional teaching, and organize appraisals Acceptance, practical training and guidance of the training of prison teachers, which can better improve the passing and certification rate of criminals' professional qualifications. Second, strengthen social adaptability training. On the one hand, the prison builds a platform and actively builds a simulation training base in the prison, invites social enterprises to provide management resources and technical support, design reasonable training projects, and jointly carry out professional ethics, professionalism, skills improvement and other aspects of adaptability training. On the other hand, it has jointly established an out-of-prison training base with social enterprises, and regularly organizes offenders to go to the base for practical exercise. Third, build a socialized return system for criminal vocational and technical education. For example: organizing social enterprises to hold job fairs in prisons to recommend offenders for employment in a targeted manner; cooperating with the Judicial Bureau to do a good job in the integration of placement, assistance and education, and relying on the "halfway home" to set up transitional placement assistance and education bases to allow offenders to enter Before entering the society, the vocational skills shall be upgraded and the transition of social adaptation shall be carried out.Fourth, relying on local government, social media and other resources, effectively increase publicity, effectively reduce the discrimination and prejudice of enterprises or some employers against prisoners released, and help the majority of released prisoners to adapt quickly The society quickly finds suitable development space for itself, and truly realizes transformation and improvement.

\section{CONCLUSION}

The education and reform of criminals is a complex systematic project. Vocational and technical education for criminals requires the extensive participation and support of the whole society. We must actively explore the socialization of criminal vocational and technical education, fully integrate beneficial social resources, and form a good coordinated development. The situation has helped improve the quality of criminal rehabilitation.It can be said that in the process of criminal vocational and technical education, the social significance of criminal vocational and technical education should be fully and comprehensively grasped. At the same time, the prominent practical problems in criminal vocational and technical education should be thoroughly and comprehensively analyzed, and efficient and scientific development should be actively adopted. The countermeasures are to maximize the quality and effectiveness of criminal vocational and technical education, comprehensively help criminals to reform, and help them better and faster adapt to the development needs of the future society.

\section{REFERENCES}

[1] Liu Bin, Demei Zeng. Thoughts on the Socialization of Vocational and Technical Education for Criminals[J]. Journal of Anhui Vocational College of Police Officers, 2019,18(6):89-92,111.

[2] Liu Bin, Zongyue Lan. The status quo and socialization of criminal vocational and technical education[J]. Journal of Liaoning Institute of Public Security and Judicial Administration, 2019, (3): 77-81.

[3] Huijian Cheng, Yuanfa Li, Xingyue Pan. Investigation and Analysis of Vocational and Technical Education of Offenders in Qinghe Branch $[\mathrm{J}]$. Research on Crime and Reform, 2012, (004): 37-40.

[4] Qingbin Zhang. Prison: the survival dilemma and breakthrough of the marginalization of modern society[J]. Chinese Justice, 2014, (7).76-80.

[5] Wang Lin. Practice and thinking on criminal labor vocational skills training in the context of prison system reform[J]. Journal of Zhengzhou Institute of Aeronautical Industry Management (Social Science Edition), 2014, (5). 134-137. 